\title{
O Pronasci' e a Violência Doméstica contra a Mulher
}

\section{The Pronasci and Domestic Violence against Women}

\section{MARCIO EVANGELISTA FERREIRA DA SILVA}

Graduado em Direito pela Universidade de Mogi das Cruzes/SP, Especialista em Direito pela Universidade Candido Mendes/RJ, Mestrando pelo UniCEUB/DF, Juiz de Direito do TJDFT desde 2003, atuando em Tribunais do Júri, Varas Criminais e Juizado de Violência Doméstica contra a Mulher, Professor de Direito Penal e Execução Penal desde 2004, Coordenador da Revista da Escola da Magistratura do TJDFT desde 2009, Ex-Advogado militante na capital de SP de 1996 a 2003, atuando em causas Cíveis e Criminais. Atualmente, leciona Direito Penal no IESB-DF, IDP-DF e no Instituto de Formação Ministro Luiz Vicente C. do TJDFT. Leciona Execução Penal na Esma/DF e IDP/DF.

Submissão: 04.02.2013

Decisão Editorial: 27.05.2013

RESUMO: 0 presente artigo aborda a questão da violência doméstica e intrafamiliar contra a mulher no Brasil, os movimentos sociais e as políticas públicas que visam à sua erradicação. Assim, é feita uma análise da história da violência doméstica contra a mulher, a edição da Lei Maria da Penha e seus efeitos quanto à taxa de homicídios, bem como se analisa a implementação dos Juizados Especializados de Violência Doméstica e Familiar contra a Mulher, uma das metas do Pronasci. A metodologia utilizada foi bibliográfica e por meio do instrumento questionário. No início, aborda-se as políticas públicas estatais e a Lei Maria da Penha sob tal enfoque. Em seguida, é feita uma análise sob o enfoque da segurança pública e do Pronasci como programa de política de Estado. Ao final, antes da conclusão, os dados empíricos coletados são analisados. Na conclusão, apresenta-se um panorama da violência doméstica e familiar contra a mulher no Brasil e se a meta do Pronasci (implementação dos Juizados Especializados de Violência Doméstica e Familiar contra a Mulher) foi atingida.

PALAVRAS-CHAVE: Violência doméstica; Lei Maria da Penha; Pronasci; Juizados Especializados.

ABSTRACT: This article addresses the issue of domestic violence against women within the family and in Brazil, social movements and public policies aimed at its eradication. Thus, an analysis is made of the history of domestic violence against women, the issue of the Maria da Penha Law and its effects as the homicide rate and analyzes the implementation of Specialized Courts for Domestic and Family Violence Against Women, a Pronasci goals. The methodology used was the literature and through the questionnaire instrument. Earlier approaches to public policy and the State Law Maria da Penha under such an approach. Then an analysis is made with a focus on public safety and Pronasci program as state policy. At the end, before completion, the empirical data collected are analyzed. The conclusion presents an overview of domestic and family violence against women in Brazil and the

Programa Nacional de Segurança Pública com Cidadania.

2 The National Public Security and Citizenship. 
meta Pronasci (Specialized Courts implementation of Family and Domestic Violence Against Women) was reached.

KEYWORDS: Domestic violence; Maria da Penha Law; Pronasci; Specialized Courts.

SUMÁRIO: Introdução; 1 Política pública; 2 A Lei Maria da Penha e as políticas públicas; 3 Política pública, segurança pública e a Lei Maria da Penha; 40 Pronasci; 5 A pesquisa empírica; Conclusão; Referências.

\section{INTRODUÇÃ̃O}

A violência contra a mulher permeia a sociedade brasileira, talvez decorrente do machismo, talvez pela vergonha que as mulheres têm de denunciar os fatos às autoridades, pois se fala que os crimes praticados no reduto do lar sempre são segredos de família (Matos; Cortes, 2011, p. 40). No entanto, a histórica violência intrafamiliar deve receber uma abordagem diferenciada (Dias, 2007, p. 8), eis que, mesmo sendo histórica a violência contra a mulher, havendo movimentos sociais ${ }^{3}$ para erradicá-la, havendo previsão constitucional para a proteção das relações familiares ${ }^{4}$ e o Brasil sendo signatário da Convenção Interamericana para Prevenir, Punir e Erradicar a Violência contra a Mulher ${ }^{5}$, constata-se que tais movimentos e dispositivos legais não foram suficientes para cessá-la, pois de 1980 a 2010 mais de 91 mil mulheres foram vítimas de homicídio no Brasil ${ }^{6}$.

Assim, para dar um tratamento diferenciado à mulher, pois o contexto é diferenciado, promulgou-se a Lei $n^{\circ}$ 11.340/2006, a chamada Lei Maria da Penha. Citada lei trouxe um arcabouço de medidas assecuratórias à muIher criando meios para protegê-la, mas também fomentando a punição ao agressor, visando, assim, a erradicar a violência de gênero. Após o início da vigência da citada lei, notou-se que os homicídios contra as mulheres tiveram ligeira queda. Com efeito, em 1996, a taxa era de 4,6 mortes por 100 mil habitantes, sendo que, em 2007, a taxa foi de 3,97.

O Pronasci lançado pelo Ex-Presidente da República, Luis Inácio Lula da Silva, em agosto de 2007, continha noventa e quatro ações estruturais e programas locais e a principal meta é promover um verdadeiro projeto de inclusão social do País. Uma das ações tem o condão de tornar efetivas as disposições da Lei Maria da Penha, sendo que a ação estrutural no 5 dispõe

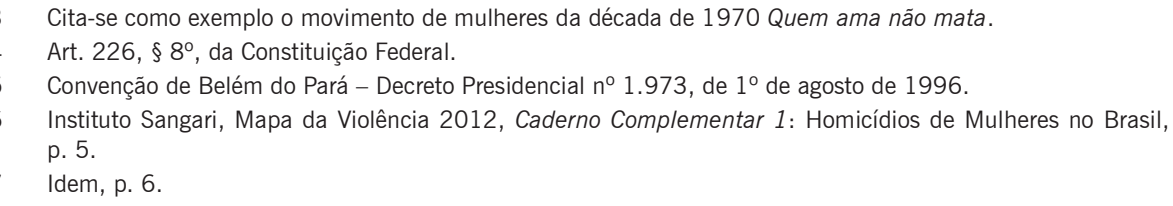


sobre uma parceria com a Secretaria Especial de Políticas para as Mulheres da Presidência da República e com o Conselho Nacional de Justiça para apoiar os órgãos do Sistema de Justiça na implementação dos serviços especializados, como os Juizados/Varas de Violência Doméstica e Familiar contra a Mulher.

Infelizmente, mesmo com tal política pública, em 2010, a taxa de homicídios femininos voltou a subir, eis que foi constatada a taxa de 4,4 mortes de mulheres por 100 mil habitantes ${ }^{8}$. Assim, contata-se que não bastou a vigência de uma lei para por fim à violência, eis que tal violência intrafamiliar persiste e vítima a mulher.

Destarte, o presente artigo visa a analisar a situação atual da implementação dos Juizados Especializados de Violência Doméstica e Familiar contra a Mulher, uma das metas do Pronasci. No início do presente artigo, faz-se uma abordagem sobre políticas públicas e a Lei Maria da Penha sob tal enfoque. Segue-se com a análise do tema sob o enfoque na segurança pública, bem como se aborda o Pronasci como programa, analisando-o como uma política de Estado. Por fim, antes da conclusão, analisam-se os dados empíricos coletados.

A metodologia adotada foi quantitativa por meio do instrumento questionário. O questionário foi enviado em meio físico a todos os Tribunais de Justiça do Brasil. Após receber resposta de dezenove unidades da Federação, os dados foram compilados resultando em uma tabela. Os resultados foram analisados, inclusive dados extras remetidos pelos Tribunais em conjunto com o questionário respondido. Na conclusão, é feita uma análise sobre o apurado na pesquisa demonstrando o resultado da política pública veiculada pelo Pronasci.

\section{POĹTICA PÚBLICA}

Para iniciar a abordagem do presente artigo, necessário se faz traçar algumas premissas. Primeiro, quando se fala em política pública, constata-se que não há um conceito uniforme, no entanto, pode-se defini-la como um

[...] fluxo de decisões públicas, orientando a manter o equilíbrio social ou a introduzir desequilíbrios destinados a modificar a realidade. [...] É possível considerá-las como estratégias que apontam para diversos fins, todos eles, de alguma forma, desejados pelos diversos grupos que participam do processo decisório. (Saravia; Ferrarezi, 2006, p. 28/29) 
De tal conceito pode-se dizer que há vários interesses em jogo e que tem a finalidade de modificar a realidade. Assim, há vários atores (grupos) com legítimos interesses, mas não há como tecer uma racionalidade, uma ordenação em que cada ator desempenha o papel esperado, pois trata-se de um processo de extrema complexidade. A finalidade, como dito, é modificar o mundo, ou seja, na consolidação da democracia, da justiça social e felicidade das pessoas (Saravia; Ferrarezi, 2006, p. 29)

Deve-se ainda abandonar a ideia limitada da análise que considera somente a perspectiva jurídica, pois é sabido que há uma impregnada cultura da filosofia do Estado e do Direito (Saravia; Ferrarezi, 2006, p. 27).

Ora, não se pode analisar uma dada situação da realidade somente com base em fundamentos da cultura jurídica que é, na maioria das vezes, desatualizada e foi contextualizada em um tempo diverso, ou seja, a atividade estatal, se baseada unicamente nas perspectivas jurídicas, não será dinâmica (Saravia; Ferrarezi, 2006, p. 21 e 24).

Tanto é que, na década de 1980, a atividade estatal adotou outro discurso, ou seja, diante da deterioração e falta de resposta aos anseios da população, passou-se a adotar a ideia de política pública (Saravia; Ferrarezi, 2006, p. 26)

No entanto, não houve uma ruptura, mas sim a coexistência dos enfoques, ou seja, se as perspectivas jurídicas são limitadas, atrelam-se a ela outras visões, pois as democracias evoluídas utilizam-se das normas jurídicas e do respeito aos direitos como fundamento da convivência social e, assim, conclui-se que as visões são complementares e não excludentes, pois a "perspectiva da política pública integra adequadamente a dimensão jurídica e esta se auxilia dos insumos que as análises de política pública lhe provêm". Diante do que foi dito, pode-se afirmar que o processo de política pública é uma "forma moderna de lidar com as incertezas decorrentes das rápidas mudanças do contexto" (Saravia; Ferrarezi, 2006, p. 21 e 27/28).

Mas, em sendo uma nova forma de análise, deve-se apontar quais as etapas de um processo de política pública, bem como que formas podem ser avaliadas. Sucintamente podem-se apontar sete etapas: agenda, elaboração, formulação, implementação, execução, acompanhamento e avaliação (Saravia; Ferrarezi, 2006, p. 33/35).

Hogwoode e Gunn apontam sete formas de avaliação: estudos de conteúdos políticos, estudos do processo das políticas, estudos de produtos de uma política, estudos de avaliação, análise de processo e análise de políticas (apud Saravia; Ferrarezi, 2006, p. 31). 
Note-se que entre as formas citadas o estudo de avaliação é o que mais se desenvolve atualmente (Saravia; Ferrarezi, 2006, p. 35), razão da escolha de tal forma no presente artigo. Visto isso, passa-se agora ao estudo específico de políticas públicas e a violência doméstica e familiar contra a mulher.

\section{A LEI MARIA DA PENHA E AS POLÍTICAS PÚBLICAS}

Como visto na Introdução do presente, a violência doméstica permeia a vida cotidiana dos cidadãos brasileiros há muito tempo e não há estatísticas sistemáticas e oficiais para apontar o grau de comprometimento dos lares brasileiros (Revista Política Nacional de Enfrentamento à Violência contra as Mulheres, 2011, p. 12). Na década de 1970, ocorreu um movimento que evidenciou a violência contra a mulher, sendo que tal movimento bradava com o slogan "quem ama não mata". O movimento chamava a atenção contra as absolvições de homens que matavam mulheres alegando que foram traídos e que estavam atuando em "legítima defesa da honra" (Matos; Cortes, 2011, p. 39).

O fundamento das absolvições cingia-se a dizer que, nos termos do art. 27 do Código Penal de 1890, "não são criminosos os que por imbecilidade nativa ou enfraquecimento senil forem absolutamente incapazes de compreensão e os que se acharem em estado de completa privação dos sentidos e da inteligência no ato de cometer o crime" (grifos meus).

Analisando a doutrina da época, verifico que o slogan citado anteriormente tinha amparo legal, pois Nélson Hungria dizia que o homicídio passional, sob a alcunha de homicídio por amor, nada mais era do que uma "contrafação monstruosa". Tal autor indagava se o sentimento amor poderia gerar tal atrocidade, eis que para ele é um nobre sentimento humano de ternura e de suave emoção (Hungria, 1942, p. 129).

A tese do homicídio por amor e por defesa da honra é resquício de uma visão antiquada até mesmo para a época, eis que, desde a edição do Código Penal vigente (1940), não era mais possível alegar que o homem matava em face de sua privação dos sentidos - excludente prevista no Código anterior.

Com efeito, tal tese foi rechaçada no atual sistema, sendo que homens que matam mulheres não estão perturbados momentaneamente, são na realidade frios e cometem o crime simulando a perversidade, e mais, os atos são calculados, sendo, então, tais homens contrabandistas da moralidade que trapaceiam no jogo da justiça praticada pelos juízes de fato (Hungria, 
1942, p. 133/134). Em passagem memorável na obra Comentários ao Código Penal, Nélson Hungria disse:

Em face do novo Código, os uxoricidas passionais não terão favor algum [...] aquele que, por simples ciúme ou meras suspeitas repete o gesto bárbaro e estúpido de Otelo terá de sofrer a pena inteira dos homicidas vulgares. (ob. cit., p. 139)

A literatura sobre crimes passionais elenca inúmeros casos de absolvições com fundamento na legítima defesa da honra, mesmo após a vigência do Código Penal de 1940 (Eluf, 2002). O caso mais famoso é citado em várias obras, qual seja, o de Docca Street, que matou sua companheira, e sua defesa alegou a malfadada legítima defesa da honra (Matos; Cortes, 2011, p. 39).

Dados apontam que, de 1997 a 2007, 41.532 mulheres foram vítimas de homicídios, sendo que na grande parte das vezes dentro dos próprios lares (Revista Política Nacional de Enfrentamento à Violência contra as MuIheres, 2011, p. 12). E mais, de 1980 a 2010, segundo dados do $\mathrm{CNJ}^{9}$, aproximadamente 91 mil mulheres foram assassinadas ${ }^{10}$.

Assim, nítida a impressão de que, mesmo após a alteração legislativa, a cultura de violência e morte contra a mulher continuava, ou seja, a Lei não impedia que a violência permeasse as residências dos brasileiros, razão do movimento feminista na década de 1970 reivindicar reformas políticas e jurídicas quanto à violência doméstica (Campos, 2011, p. 143). A mulher em situação de violência doméstica é vulnerável, pois não tem capacidade de denunciar os delitos, sendo, pois, vitimizada (Zaffaroni; Batista, p. 55). Diante do flagrante quadro de violência de gênero, pois não se via crimes de mulheres contra maridos infiéis, o tema virou pauta da agenda estatal. Como visto anteriormente, a agenda é o primeiro passo para uma política pública.

Com o assunto na agenda política, o Estado estabeleceu políticas que acarretaram várias alterações no cenário em comento, no entanto, mesmo com tantos progressos, verificou-se que o gênero era um fator importante a ser considerado, eis que se trata do primeiro meio de articulação de poder (Campos, 2011, p. 3).

Das alterações decorrentes da política pública citada pode-se destacar (Campos, 2011, p. 143):

(a) criação de delegacias especializadas no atendimento a mulheres;

9 Conselho Nacional de Justiça.

10 Disponível em: www.conjur.com.br. Acesso em: 8 ago. 2012. 
(b) reforma da legislação com inclusão da violência doméstica como circunstância agravante ou qualificadora de crimes;

(c) a mudança de interpretação doutrinária e jurisprudencial dos crimes praticados com violência doméstica;

(d) a alteração na interpretação doutrinária e jurisprudencial da tese da legítima defesa da honra nos crimes de adultério;

(e) revogação de inúmeros tipos penais discriminatórios;

(f) a modificação na redação do crime de estupro;

(g) a revogação do dispositivo que permitia a extinção da punibilidade com o casamento da vítima com seu ofensor nos crimes sexuais.

Em que pesem tantas mudanças, foram tímidas e não amenizaram o problema das mulheres ameaçadas e violadas no seio de seu lar (Matos; Cortes, 2011, p. 39/40). Ou seja, não foram suficientes, eis que ainda persistia a violência contra a mulher nas relações domésticas, mormente pelo fato de ser considerada de menor potencial ofensivo nos termos da Lei no 9.099/1995, ou seja, considerada "briguinha de casal, em que ninguém deveria pôr a colher". E mais, 90\% dos casos de violência doméstica contra a mulher eram arquivados em audiências preliminares sem nenhuma resposta, tanto ao agressor quanto à vítima (Matos; Cortes, 2011, p. 41/42).

Assim, o assunto continuou na agenda, e, em 2003, foi criada a Secretaria de Políticas para as Mulheres, que estabeleceu ações para o enfrentamento à violência contra a mulher, passando a ter investimento na área (Revista Política Nacional de Enfrentamento à Violência contra as Mulheres, 2011, p. 16).

Em seguida, por força de atores militando no interesse da pauta violência contra a mulher, foi proposta a edição de uma legislação específica com fundamento em análise das legislações de outros países, e, após audiências públicas nos Estados brasileiros, o projeto foi aprovado e remetido à sanção presidencial, entrando em vigência a Lei no 11.340/2006, sob o título Lei Maria da Penha (Matos; Cortes, 2011, p. 43, 49 e 55)

Mas só a edição da lei não foi suficiente, eis que os dados demonstraram que a violência contra a mulher nos lares continuava presente, eis que, de agosto de 2006 a julho de 2007, a Viva ${ }^{11}$ apresentou um relatório de que em 27 Municípios de 8.914 notificações, 74\% referiam-se a vítimas do sexo feminino (Revista Política Nacional de Enfrentamento à Violência contra as Mulheres, 2011, p. 13).

11 Vigilância de Violência e Acidentes do Ministério da Saúde. 
Por conseguinte, diante da situação apresentada, em agosto de 2007, o Governo Federal incluiu a violência contra a mulher em sua agenda social e, consolidando o tema como política pública, lançou o Pacto Nacional de Enfrentamento à Violência contra as Mulheres (Revista Política Nacional de Enfrentamento à Violência contra as Mulheres, 2011, p. 17).

Tal pacto nada mais é do que um conjunto de ações de enfrentamento à violência contra a mulher no plano Federal, Estadual e Municipal mediante acordo como intuito de enfrentar o tema de forma transversal e intersetorial (REVISTA: Política Nacional de Enfrentamento à Violência contra as Mulheres: 2011, p. 17).

Entre as ações, uma delas chama a atenção, qual seja, a Garantia de Acesso à Justiça por Mulheres em Situação de Violência. Tal ação tem como eixo de ação e articulação de política pública "garantir o acesso à Justiça de forma que todas as mulheres possam receber atendimento adequado por meio de atuação em rede, e que os equipamentos da justiça promovam sua plena defesa e o exercício da sua cidadania" (Revista Pacto Nacional pelo Enfrentamento à Violência contra as Mulheres, 2011, p. 12/13).

O pacto traz, ainda, no Eixo I - Garantia da Aplicabilidade da Lei Maria da Penha, como ação 2 - Implementação da Lei Maria da Penha, na alínea a - "ampliação do número de juizados e varas especializadas de violência doméstica e familiar à mulher" (Revista Pacto Nacional pelo Enfrentamento à Violência contra as Mulheres, 2011, p. 28).

Reforçando as ideias do pacto, o CNJ publicou a Resolução no 9 em 8 de agosto de 2007, instando os Tribunais de Justiça dos Estados a criarem os Juizados Especializados de Violência Doméstica e Familiar contra a Mulher.

Desde agosto de 2007, Varas Especializadas foram criadas, sendo que, em 20 de setembro de 2011, foram contabilizados noventa e quatro juizados em todo o Brasil (Revista Rede de Enfrentamento à Violência contra as Mulheres, 2011, p. 18). O acesso à justiça em geral, não só às mulheres em situação de violência, é um dado importante para a consolidação da democracia, devendo ser uma ação urgente, sob pena de não podermos chamar o Estado de democrático, pois o acesso à justiça deve ser geral e universal (Mendez; Pinheiro, 2000, p. 23 e 248).

\section{POĹIIICA PÚBLICA, SEGURANÇA PÚBLICA E A LEI MARIA DA PENHA}

Já foi visto anteriormente que política pública é um conjunto de ações que visa a modificar o mundo para a consolidação da democracia, da justiça social e felicidade das pessoas. Mas qual a relação entre política pública, 
segurança pública e a Lei Maria da Penha? São indagações que demandam longo estudo e pesquisas, no entanto, é possível traçar algumas linhas sobre o assunto. Com efeito, segurança pública, desde a década de 1980, é tema de debate internacional, no entanto, a questão criminal não é mais só assunto da justiça, mas tema transversal de um conjunto de políticas públicas, ou seja, enfatiza-se "o caráter interdisciplinar e multifatorial do tema" (Dias Neto, 2005, p. 17).

Segurança pública não é só o combate à criminalidade, mas também a "luta por uma sociedade fundada na realização das necessidades reais, das potencialidades de desenvolvimento dos indivíduos e dos povos (Baratta: 2000, p. 3). Mas alerta-se, o tema segurança pública não pode destoar para a legislação de emergência no intuito de apresentar resultados das políticas públicas. Melhor esclarecendo, a legislação de emergência com o fito de nortear a segurança pública perde "seu caráter de 'direitos assegurados e regulados' para se converter em 'instrumentos de poder' à disposição do Executivo, para a 'obtenção de resultados substantivos nos planos econômico, político e social'" (Dias Neto, 2005, p. 31).

Assim, na abordagem do direito penal, não se pode ter o foco segurança a qualquer custo em detrimento da política de segurança, eis que não se pode adotar políticas penais que "não estão voltadas à mobilização das esferas públicas visando ao enfrentamento racional e preventivo dos conflitos e das situações associados diretamente ou indiretamente ao sentimento de insegurança" (Dias Neto, 2005, p. 71).

Diante do que foi dito, indaga-se: a Lei Maria da Penha como política pública traz segurança pública? É cedo ainda para dizer quais os efeitos da nova legislação de proteção das mulheres em situação de violência doméstica, mas os dados estatísticos revelam que as mulheres estão tendo mais acesso à justiça e denunciando a violência que Ihes achacam há muito ${ }^{12}$.

Mas ainda há dúvidas se todos os planos políticos que culminaram na edição da Lei Maria da Penha foram implementados, sendo um deles a criação no Brasil de Juizados de Violência Doméstica e Familiar contra a Mulher. Outro ponto a ser esclarecido é se a rede de apoio às mulheres vítimas de violência doméstica foi implementado, pois a necessidade de segurança não pode deixar de se articular como demanda política transversal para se expressar unicamente "pelo vocabulário pena", pois se assim for, os problemas deixam de ser políticos e passam a ser "policializados" (Dias Neto, 2005, p. 89).

12 Cf. dados do CNJ foram julgadas 408 mil ações envolvendo violência doméstica desde a criação da Lei Maria da Penha. 


\section{E mais:}

Temas como a delinquência juvenil, violência doméstica, alcoolismo ou incivilidade no trânsito adquirem contornos bastante distintos se analisados da perspectiva policial, psicológica, médica, legal, assistencial ou urbanística. Podem justificar intervenções policiais repressivas, que podem ser apropriadas e legítimas levando-se em conta o interesse de preservação da ordem pública ou de apuração de culpabilidade, mas que podem ser extremamente contraprodutivas da perspectiva terapêutica, preocupada com a estabilidade das relações familiares ou com aspectos emocionais do autor. (Dias Neto, 2005, p. 143) (grifos meus)

Portanto, a análise de política pública, da segurança pública e da Lei Maria da Penha deve observar tais fatores, ou seja, não basta reprimir penalmente, deve haver uma rede interdisciplinar para abordar o assunto sob pena de criarmos novos criminosos pelo processo de seleção penal.

\section{PRONASCI}

O Programa Nacional de Segurança Pública com Cidadania - Pronasci, lançado pelo Ex-Presidente da República, Luis Inácio Lula da Silva (agosto de 2007), tem a intenção de, em síntese, por meio das noventa e quatro ações Estruturais e Programas Locais, fazer com que o Estado seja uma instituição intimamente ligada à construção da dignidade de todos.

É sabido que a segurança política, jurídica e econômica é elemento central para a construção de uma sociedade democrática, ou seja, é uma conquista daqueles que têm os seus direitos violados em situação de instabilidade. Assim, quando da elaboração das ações estruturais do Pronasci, ficou evidente que, para promover um verdadeiro projeto de inclusão social do País, era necessário implementar políticas públicas para tornar efetivas as disposições da Lei no 11.340/2006 - a chamada Lei Maria da Penha.

Como visto anteriormente, várias foram as ações, sendo que a Ação Estrutural $n^{\circ} 5$ dispõe:

Efetivação da Lei Maria da Penha. Em parceria com a Secretaria Especial de Políticas para as Mulheres da Presidência da República e com o Conselho Nacional de Justiça, o Pronasci apoia os órgãos do Sistema de Justiça na implementação dos serviços especializados previstos na Lei Maria da Penha (Lei no 11.340/2006), como Juizados/Varas de Violência Doméstica e familiar contra a Mulher, Núcleos de Atendimento à Mulher da Defensoria Pública e Núcleos/Promotorias de Justiça do Ministério Público.

\section{A PESQUISA EMPÍRICA}

Para a análise do sucesso ou não do programa citado anteriormente, ou seja, para a pesquisa empírica de eventual resultado sobre o tema pós- 
-Pronasci, escolheu-se o questionário, eis que o universo de todos os Estados e o Distrito Federal exigia (Fonseca, 2009, p. 85).

O questionário nada mais é do que um instrumento que indica os objetivos específicos da pesquisa redigidos de forma clara e precisa. A escolha do questionário com perguntas fechadas e objetivas se deu para meIhor codificar o trabalho em um quadro estatístico (Figueiredo; Souza, 2008, p. 127 e 129/130).

No citado questionário, indagou-se, de todos os presidentes dos Tribunais de Justiça dos Estados e do Distrito Federal, se foram criadas Varas Especializadas em Violência Doméstica e Familiar contra a Mulher, se a instalação ocorreu após o Pronasci, se a instalação ocorreu com recursos próprios do Tribunal de Justiça, se a instalação da Vara Especializada ocorreu em decorrência de parceria com a Presidência da República - Secretaria Especial de Políticas para Mulheres, se a instalação da Vara Especializada ocorreu em decorrência de parceria com o Conselho Nacional de Justiça e se com a instalação da Vara Especializada foi criada equipe multidisciplinar para acompanhar os casos em trâmite perante o citado juízo. A título de ilustração, segue minuta do questionário elaborado:

1 - O Tribunal criou varas especializadas em Violência Doméstica e Familiar contra a Mulher?

( ) $\operatorname{SIM}($ ) NÃO

2 - Em caso positivo ao questionamento anterior, a instalação da vara especializada ocorreu após o Pronasci?

( ) $\operatorname{SIM}($ ) NÃO

3 - Ainda em caso positivo ao questionamento $n^{\circ}$ 1, a instalação da vara especializada ocorreu com recursos próprios do Tribunal de Justiça?

( ) $\operatorname{SIM}($ ) NÃO

4 - Ainda em caso positivo ao questionamento $n^{\circ}$ 1, a instalação da vara especializada ocorreu em decorrência de parceria com a Presidência da República - Secretaria Especial de Políticas para Mulheres?

( ) $\operatorname{SIM}($ ) NÃO

5 - Ainda em caso positivo ao questionamento $\mathrm{n}^{\circ}$ 1, a instalação da vara especializada ocorreu em decorrência de parceria com o Conselho Nacional de Justiça?

( ) $\operatorname{SIM}($ ) NÃO 
6 - Ainda em caso positivo ao questionamento $\mathrm{n}^{\circ} \mathbf{1}$, com a instalação da vara especializada, o Tribunal de Justiça criou equipe multidisciplinar para acompanhar os casos em tramite perante o citado juízo?

( ) $\operatorname{SIM}($ ) NÃO

Trata-se de questionário simples com o intuito de evitar rejeição, no entanto, os elementos colhidos são de suma importância, pois apontam a real situação pós-Pronasci.

O questionário foi enviado em junho de 2012 a todos os Tribunais de Justiça do País via correio, solicitando-se que a resposta fosse enviada pelo mesmo meio ou por via eletrônica (e-mail).

Do período de $1^{\circ}$ de julho a 17 de setembro de 2012, foram recebidas, por e-mail e por carta, respostas de dezoito Estados (TJTO, TJSP, TJSC, TJPR, TJMTS, TJES, TJGO, TJCE, TJAP, TJRR, TJMG, TJRJ, TJAM, TJMA, TJMT, TJRS, TJBA, TJPA) e do Distrito Federal (TJDFT). Infelizmente, os demais Estados não responderam até o momento, fazendo com que a pesquisa - que tinha intenção de ser nacional - limite-se a tais localidades.

A ausência de respostas ao questionário por parte dos Tribunais, em que pese a pesquisa ser fundamentada na Lei de Informação ${ }^{13}$, era esperada, pois, conforme Lakatos, o retorno é em torno de 25\% (Lakatos; Marconi, 1996, p. 201). E mais, não há uma tradição no Brasil em pesquisas empíricas de tal natureza, bem como fica-se à mercê da boa vontade do pesquisado em responder o questionamento (Fonseca, 2009, p. 86).

No entanto, o parcial retorno ao questionário não abala a credibilidade da pesquisa, eis que, como dito, além de ser esperado, a pesquisa científica considera o mínimo exigido em torno de 25 a 30\% (Fonseca, 2009, p. 86).

Segue tabela dos dados colhidos com a pesquisa.

\begin{tabular}{|c|c|c|c|}
\hline & $\begin{array}{c}\text { RESULTADOS DO QUESTIONÁRIO SOBRE A IMPLEMENTA- } \\
\text { ÇÃO DA AÇÃO ESTRUTURAL No }\end{array}$ \\
\hline & R DO PRONASCI
\end{tabular}

13 Lei $\mathrm{n}^{\circ} 12.527$, de 18 de novembro de 2011. 


\begin{tabular}{|c|c|c|c|}
\hline \multicolumn{4}{|c|}{$\begin{array}{l}\text { RESULTADOS DO QUESTIONÁRIO SOBRE A IMPLEMENTA- } \\
\text { ÇÃO DA AÇÃO ESTRUTURAL № } 5 \text { DO PRONASCI }\end{array}$} \\
\hline & Resposta SIM & Resposta NÃO & Porcentagem \\
\hline Questão nº 4 & 2 & 17 & $10,5 \%$ \\
\hline Questão no 5 & 1 & 18 & $5,2 \%$ \\
\hline Questão no $6^{14}$ & 17 & 1 & $95 \%$ \\
\hline
\end{tabular}

Saliente-se que alguns Tribunais, ao prestarem as informações, teceram comentários, enriquecendo ainda mais a pesquisa. Passo, então, a analisar os dados colhidos item por item - inclusive expondo dados extras fornecidos pelos Tribunais.

1 - O Tribunal criou varas especializadas em Violência Doméstica e Familiar contra a Mulher?

De acordo com as repostas ao questionário, pode-se afirmar que $100 \%$ das localidades possuem Juizados Especializados em Violência Doméstica e Familiar contra a mulher.

2 - Em caso positivo ao questionamento anterior, a instalação da vara especializada ocorreu após o Pronasci?

Observou-se que em $68 \%$ das localidades os juízos especializados em violência doméstica contra a mulher foram criados após a Ação Estrutural $n^{\circ} 5$ do Pronasci, sendo que somente uma localidade (TJRJ) relatou que instalou dois juizados antes do Pronasci e outros após. Note-se que outra localidade (TJPR) apontou que o juizado não foi criado após a citada ação estrutural, levando-nos a crer que ocorreu antes, eis que referido Tribunal assentou que possui o juizado especializado.

3 - Ainda em caso positivo ao questionamento $n^{0} 1$, a instalação da vara especializada ocorreu com recursos próprios do Tribunal de Justiça?

De acordo com as repostas ao questionário, 68\% das localidades instalaram os juizados especializados com recursos do próprio Tribunal.

Note-se que dois Tribunais (TJMG, TJRJ) argumentaram que, além de verbas do próprio Tribunal, receberam também verbas do Ministério da Justiça por meio da Secretaria de Reforma do Judiciário. Acredito que, de

14 O Tribunal de Justiça do Pará deixou de responder a tal questionamento e não justificou. 
alguma forma, houve confusão, eis que outros Tribunais, ao responderem ao questionamento $\mathrm{n}^{\circ} 4$, relataram que efetivaram parceria com o Ministério da Justiça/Secretaria de Reforma do Judiciário - via Pronasci, c. p. e. o TJAP, ou seja, pode ocorrer que Tribunais utilizaram-se de verbas do Pronasci pensando serem do Ministério da Justiça.

4 - Ainda em caso positivo ao questionamento $n^{\circ} 1$, a instalação da vara especializada ocorreu em decorrência de parceria com a Presidência da República - Secretaria Especial de Políticas para Mulheres?

De acordo com as repostas ao questionário, pode-se afirmar que apenas $10,5 \%$ das localidades instalaram os juizados com parceria com a Secretaria Especial de Políticas para Mulheres da Presidência da República. Note-se que alguns Tribunais (TJDFT, TJTO, TJAP e TJMG) comentaram o questionamento, relatando que se utilizaram de verbas do Pronasci, verbas do Ministério da Justiça (reforma do judiciário) e verbas próprias para instalar mais juízos especializados.

5 - Ainda em caso positivo ao questionamento $n^{\circ} 1$, a instalação da vara especializada ocorreu em decorrência de parceria com o Conselho Nacional de Justiça?

Quanto à participação do CNJ na instalação de juizados especializados de violência doméstica e familiar contra a mulher, apenas uma das localidades (TJDFT) relatou que houve parceria. Tal localidade narrou que a participação do citado órgão ocorreu no fomento de estudos quanto à necessidade de criação de novos juízos especializados.

6 - Ainda em caso positivo ao questionamento $n^{-0} 1$, com a instalação da vara especializada, o Tribunal de Justiça criou equipe multidisciplinar para acompanhar os casos em trâmite perante o citado juízo?

Notou-se que $95 \%$ das localidades, ao instalarem o juizado especial de violência doméstica e familiar contra a mulher, também criaram equipe multidisciplinar. Somente uma localidade (TJMG) relatou que não criou citada equipe, no entanto, asseverou que o juízo especializado conta com uma psicóloga e duas assistentes sociais do quadro de pessoal do citado Tribunal. Note-se que o TJPA não respondeu ao questionamento.

Por fim, embora alguns Tribunais não tenham respondido aos questionamentos, em consulta realizada perante o portal eletrônico da $\mathrm{AMB}^{15}$, constatou-se que somente o Tribunal de Sergipe ainda não dispõe de jui-

15 Associação dos Magistrados Brasileiros. Disponível em: <www.amb.com.br/fonavid/Juizados_RELACAO_DE_ JUIZADOS.pdf>. Acesso em: 14 set. 2012. 
zado especializado, no entanto, não é possível asseverar se os Tribunais que não participaram da pesquisa, ao criarem os juizados especializados, implementaram a ação do Pronasci, com ou sem parceria com o Pronasci, CNJ, Presidência da República, etc.

\section{CONCLUSÃO}

Pois bem, vimos que a violência doméstica e familiar contra a mulher é fato cultural e antigo que gerou movimentos sociais que colheram frutos chamando a atenção sobre o tema. Não se discute mais que definitivamente o tema violência doméstica está na agenda de Políticas Públicas Federal, Estadual e Municipal, ou seja, fruto dos movimentos sociais de combate à violência intrafamiliar. $\mathrm{O}$ movimento citado no início do presente artigo conseguiu que políticas públicas fossem implementadas, bem como que paradigmas doutrinários e jurisprudenciais fossem alterados. Com efeito, a doutrina brasileira - na grande maioria - reconhece a Lei Maria da Penha como um avanço em coibir a violência de gênero.

A jurisprudência, a passos largos, reconhece diuturnamente que a violência contra a mulher não é um delito de menor potencial ofensivo ${ }^{16}$. Recentemente, o CNJ apresentou uma pesquisa que aponta ter o Poder Judiciário julgado 408 mil ações envolvendo violência contra a mulher entre 685.905 procedimentos correlatos ${ }^{17}$.

Tais dados indicam que ainda há muito a fazer, pois em que pese todo o esforço dos movimentos desde a década de 1970, a violência contra a mulher na unidade familiar ainda persiste. Diante do quadro pesquisado no presente trabalho, pode-se afirmar que os Estados estão dotados de juizados especializados para o atendimento à mulher vítima de violência, ou seja, o acesso à justiça está sendo fomentado. No entanto, não basta envidar esforços para o acesso à justiça se a rede de apoio não for também implementada, eis que, conforme dito, a segurança pública é questão interdisciplinar e multifatorial.

Um alento é o Programa Políticas para as Mulheres: Enfrentamento à Violência e Autonomia (PPA - 2012-2015), ou seja, o problema ainda é pauta da agenda do Governo Federal e traz como meta principal ampliar e fortalecer a rede de atendimento às mulheres em situação de violência, tendo ainda como objetivo fortalecer a implementação da Lei Maria da Penha e contribuir para o aumento de Juizados e Varas Especializadas de violência doméstica e familiar contra a mulher.

16 O Supremo Tribunal Federal assentou que não se aplica as disposições da Lei nº 9.099/1995 aos delitos que envolvem a Lei Maria da Penha (ADIn 4424).

17 Disponível em: www.conjur.com.br. Acesso em: 8 ago. 2012. 
No entanto, como dito, a análise deve ser sistêmica e considerar todos os atores da órbita judicial, tais como juízes, Ministério Público, serventuários, auxiliares, advogados, defensoria pública, organizações profissionais (Zaffaroni; Nilo, p. 61), ou seja, não basta que se criem novas Varas Especializadas, deve-se criar as Varas Especializadas em conjunto com a rede de apoio - abrigos, serviço social, psicológico e assessoria jurídica -, pois, do contrário, a Lei Maria da Penha sofre o risco de ser rotulada de oriunda do movimento de Lei e Ordem ${ }^{18}$.

\section{REFERÊNCIAS}

BARATTA, Alessandro. UCAM, Rio de Janeiro, 2000 (MIMEO)

CAMPOS, Carmen Hein. Razão e sensibilidade: teoria feminista do direito de Lei Maria da Penha. In: Lei Maria da Penha, comentada em uma perspectiva jurídico-feminista. São Paulo: Lumen Juris, 2011.

DIAS, Maria Berenice. A Lei Maria da Penha na Justiça. São Paulo: RT, 2007.

DIAS NETO, Theodomiro. Segurança urbana. São Paulo: RT, 2005.

ELUF, Luiza Nagib. A paixão no banco dos réus. São Paulo: Saraiva, 2003.

FIGUEIREDO, Antônio Macena de; SOUZA, Soraia Riva Goudinho. Projetos, monografias, dissertações e teses. Rio de Janeiro: Lumem Juris, 2008.

FONSECA, Maria Guadalupe Piragibe da. Iniciação à pesquisa no direito. São Paulo: Campus/Elsevier, 2009.

HUNGRIA, Nélson. Comentários ao Código Penal. Rio de Janeiro: Forense, 1942.

LAKATOS, Eva Maria; MARCONI, Marina de Andrade. Fundamentos de metodologia científica. São Paulo: Atlas, 1996.

MATOS, Myllena Calazans; CORTES, láris. O processo de criação, aprovação e implementação da Lei Maria da Penha. In: Lei Maria da Penha, comentada em uma perspectiva jurídico-feminista. São Paulo: Lumen Juris, 2011.

MENDEZ, Juan E.; O'DONNELL, Guillermo; PINHEIRO, Paulo Sérgio. Democracia, violência e injustiça, o não-estado de direito na América Latina. São Paulo: Paz e Terra, 2000.

REVISTA Política Nacional de Enfrentamento à Violência contra as Mulheres, Secretaria de Políticas para as Mulheres, Presidência da República, Coleção Enfrentamento à Violência contra as Mulheres, Brasília, 2011.

REVISTA Pacto Nacional pelo Enfrentamento à Violência contra as Mulheres, Secretaria de Políticas para as Mulheres, Presidência da República, Coleção Enfrentamento à Violência contra as Mulheres, Brasília, 2011.

18 Movimento que reivindica maior repressão afirmando que não se reprime suficientemente ( ZAFFARONI, E. Raúl; BATISTA, Nilo. Direito penal brasileiro, primeiro volume, teoria geral do direito penal. Rio de Janeiro: Revan, 2003. p. 63). 
REVISTA Rede de Enfrentamento à Violência contra as Mulheres, Secretaria de Políticas para as Mulheres, Presidência da República, Coleção Enfrentamento à Violência contra as Mulheres, Brasília, 2011.

WAISELFISZ, Julio Jacobo. Os novos padrões da violência homicida no Brasil, Revista Mapa da Violência 2012, São Paulo, Instituto Sangari, 2011 - Caderno Complementar 1: Homicídio de Mulheres no Brasil.

SARAVIA, Enrique; FERRAREZI, Elisabete. Políticas públicas, coletânea. Brasília: ENAP, v. 1, 2006.

ZAFFARONI, E. Raúl; BATISTA, Nilo. Direito penal brasileiro, primeiro volume, teoria geral do direito penal. Rio de Janeiro: Revan, 2003. 